\title{
Article
}

\section{Effects of a patellar strap on knee joint kinetics and kinematics during jump landings: an exploration using a statistical parametric mapping and Bayesian approach}

Sinclair, Jonathan Kenneth, Taylor, Paul John, Brooks, Darrell and Glenn, Thomas

Available at http://clok.uclan.ac.uk/29432/

Sinclair, Jonathan Kenneth ORCID: 0000-0002-2231-3732, Taylor, Paul John ORCID: 0000-0002-9999-8397, Brooks, Darrell ORCID: 0000-0002-4094-5266 and Glenn, Thomas (2019) Effects of a patellar strap on knee joint kinetics and kinematics during jump landings: an exploration using a statistical parametric mapping and Bayesian approach. Sport Sciences for Health . ISSN $1824-7490$

It is advisable to refer to the publisher's version if you intend to cite from the work. http://dx.doi.org/10.1007/s11332-019-00589-3

For more information about UCLan's research in this area go to http://www.uclan.ac.uk/researchgroups/ and search for <name of research Group>.

For information about Research generally at UCLan please go to http://www.uclan.ac.uk/research/

All outputs in CLoK are protected by Intellectual Property Rights law, including Copyright law. Copyright, IPR and Moral Rights for the works on this site are retained by the individual authors and/or other copyright owners. Terms and conditions for use of this material are defined in the policies page. 
14 Faculty of Health and Wellbeing

15 University of Central Lancashire

16 Preston

17 Lancashire

PR1 2HE.

e-mail: jksinclair@uclan.ac.uk

Keywords: Biomechanics; patellar tendon strap; kinetics; kinematics.
Lancashire, Lancashire, UK.

3. School of Medicine, Faculty of Clinical \& Biomedical Sciences, University of Central Lancashire, Lancashire, UK. 


\section{Abstract}

PURPOSE: The aim of the current research was to investigate the effects of a patellar tendon strap on knee joint kinetics and kinematics during a vertical jump task using a statistical parametric mapping (SPM) and Bayesian approach.

METHODS: Twenty-eight (14 male and 14 female) participants performed a vertical jump task under two conditions (patellar tendon strap/ no-patellar tendon strap). Biomechanical data was captured using an eight-camera 3D motion capture system and force platform. Participants also subjectively rated the comfort/ stability properties of the patellar tendon strap and their knee joint proprioception was examined with and without the strap using a weight bearing joint position sense test. Differences between patellar tendon strap/ no-patellar tendon strap conditions were examined using SPM and Bayesian analyses and subjective ratings using Chi-squared tests.

RESULTS: The results showed that neither knee joint kinetics or kinematics were affected as a function of wearing the patellar tendon strap. The findings did show that the knee brace helped to significantly increase participants perceived knee stability, but there were no improvements in weight bearing knee proprioception.

CONCLUSIONS: The current investigation indicates that the utilization of a patellar tendon strap akin to the device used in the current study does not appear to reduce the biomechanical parameters linked to the aetiology of knee pathologies, during vertical jump movements.

\section{Introduction}

The physiological and psychological benefits of physical activity, sport and exercise are wellestablished (1); and physical inactivity is recognised as one of the principal amendable risk 
45 factors linked to cardiovascular and other chronic pathologies such as type II diabetes mellitus, cancer, hypertension and depressive symptoms (2). Therefore, several national/ international initiatives have been introduced, seeking to encourage the adoption of a physically active lifestyle (3).

However, despite the incontrovertible health benefits that are mediated through regular physical activity, they are also known to be associated with a high incidence of musculoskeletal injury (4). Injury is viewed as the only drawback of regular physical activity, but is unfortunately recognised as a common complaint associated with substantial issues (5). The management/ treatment of injuries associated with physical activity and sport is challenging for both patients and clinicians, and places significant economic stresses on the global healthcare system (6).

Importantly, Hootman et al., (7) observed in an examination of 15 different sports, that the lower extremities were the most common location for injury. Specifically, the knee has been shown to be the most commonly injured musculoskeletal site in athletes, accounting for 23.2$31 \%$ of all sports injuries (8) and as many as $60 \%$ of all sports-related surgeries (9). Furthermore, a significant proportion of those partaking in physical activity and exercise will experience knee pain each year (10), with a significant proportion being associated with patellar tendinopathy and patellofemoral pain syndrome $(11,12)$.

66 Chronic patellar tendinopathy (often referred to as jumper's knee) is a musculoskeletal condition, responsible in both recreational and elite athletes, for as many as $25 \%$ of all soft 
tissue injuries (13). Patellar tendinopathy is epitomized by localized pain and tenderness of the tendon itself at its proximal origin on the inferior pole of the patella (14). This condition is mediated by activities that frequently and excessively load the patellar tendon, with failed reparative response due to insufficient rest between bouts of exercise/ training (15). It has therefore been recommended that treatment strategies for patellar tendinopathy concentrate on reducing the loading of the tendon (16). Chronic tendinopathy is initiated 1-3 months after the commencement of pain symptoms (17), mediated by the absence of inflammatory cells within the tendon itself (16). The pathological region at the inferior pole of the patellar is distinct, in that tendinopathy is associated with relative growth of the tendinous tissue, disorganisation of the collagen fibers, and a reduction in differentiation between adjoining collagen bundles (18). Patellar tendinopathy is known to be both recurring and debilitating for those seeking to engage in physical activity, sport and exercise (12). Cook et al., (19) revealed that $>33 \%$ of those experiencing patellar tendinopathy were unable to return to their habitual physical activity regime within 6 months. Even more concerning were the observations of Kettunen et al., (20) that $53 \%$ of athletes presenting with this pathology were forced to permanently withdraw from their chosen sport.

Similarly, patellofemoral pain, which typically manifests as retropatellar or diffuse peripatellar pain (21), is renowned as the most predominant orthopaedic condition in sports medicine (22). The total occurrence of patellofemoral pain ranges from $8.8-17 \%$ (23); although the incidence rate is considerably greater in active populations, with a recent observational analysis indicating that $25 \%$ of female and $18 \%$ of male athletes were affected (24). Pain symptoms force $74 \%$ of patients to attenuate their engagement with sport/ physical activity, and causes many athletes to permanently, and prematurely end their participation in sport (25). Therefore, many patellofemoral pain patients develop associated psychological 
93 disorders including mental distress, pain-related fear, reduced self-efficacy and kinesiophobia

$(26,27)$. Patellofemoral pain is exasperated by athletic tasks/ disciplines that frequently and excessively load the joint (21), and elevated patellofemoral joint stress (28), knee flexion, and knee adduction (29) are regarded as the biomechanical factors most strongly linked to the development of patellofemoral pain. Although treatment efficacy for patellofemoral pain is promising in the short term, the longer-term prognosis is poor, with between $71-91 \%$ of individuals facing ongoing symptoms up to 20 years following diagnosis (30). Importantly, those who experience patellofemoral symptoms may later present with radiographic evidence of osteoarthritis at this joint (31).

Because both patellar tendinopathy and patellofemoral pain syndrome typically necessitate expensive long-term rehabilitation regimes $(16,32)$, prophylactic modalities are becoming increasingly important. The patellar tendon strap, a band worn just below the knee, in the soft tissue between the pole of the patella and tibial tubercule, is one of the most frequently adopted external devices for the treatment/ circumvention of knee pathologies (33). However, despite their frequent utilization, there has been relatively little research attention related to the efficacy of patellar tendon straps in reducing risk from chronic knee injuries.

Lavagnino et al., (14), examined the effects of a patellar tendon strap on localized strain at the proximal aspect of the patellar tendon typically affected by tendinopathy. They measured participants in a static position during weight bearing and non-weight bearing and quantified tendon strain using radiographic images. Their findings confirmed that localized strain was significantly decreased as a function of using the tendon strap, from which it was concluded that they may limit excessive patella tendon strain. Demirbüken et al., (33) examined the 
influence of a patellar tendon strap on weight-bearing asymmetry during squatting in those with and without knee osteoarthritis. The findings of this analysis showed that no statistical improvements were mediated as a function of the patellar tendon strap. Rosen et al., (34) examined the acute effects of a patellar tendon strap during single-limb landings in athletes with and without patellar tendinopathy. Patellar tendon straps reduced self-reported pain, produced less hip rotation, knee adduction, ankle inversion and decreased landing forces in those with patellar tendinopathy. Rosen et al., (35) similarly examined the influence of patellar tendon straps on quadriceps' muscle activity during drop-jump landings in male athletes with and without patellar tendinopathy. Their findings showed that in both tendinopathy and control groups, the patellar tendon strap reduced vastus lateralis preactivation. Finally, both de Vries et al., (36) and de Vries et al., (37) who examined proprioception using a knee joint position sense test found that knee joint proprioception was enhanced in those with low proprioceptive acuity. To date however, there has yet to be any chronic knee pathologies.

Finally, whilst clinical musculoskeletal literature has made significant progress in identifying (SPM) may therefore represent a more effective process for the analysis of time-based data, as it is able to explore an entire data series (39). This removes potential bias in the extraction of individual discrete variables, and also reduces the likelihood of a type II error by 
eliminating requirement for multiple analyses (40). Similarly, Bayesian analyses have also become considerably more prevalent and practicable in the last decade years (41). Nonetheless, despite their prospective benefits (42) and the plethora of statistical publications supporting their adoption, their utilization in biomechanical analyses remains limited. To date there has yet to be any biomechanical investigation which has examined the effects of different patellar tendon straps on the biomechanical parameters linked to the aetiology of chronic knee pathologies using an SPM and Bayesian approach.

Therefore, the aim of the current investigation was to examine the influence of a patellar tendon strap on knee joint kinetics and kinematics during the vertical jump, using SPM and Bayesian analyses. An investigation of this nature may provide important clinical information to athletes and physical therapists regarding the prophylactic efficacy patellar tendon straps for the attenuation of biomechanical parameters linked to the aetiology of chronic knee pathologies.

\section{Methods}

\section{Participants}

Fourteen male $($ age $=27.71 \pm 5.50$ years, height $=1.77 \pm 0.05 \mathrm{~m}$, mass $=73.51 \pm 5.69 \mathrm{~kg})$ and fourteen female $($ age $=28.00 \pm 4.96$ years, height $=1.66 \pm 0.04 \mathrm{~m}$, mass $=64.43 \pm 2.62$ $\mathrm{kg}$ ) were recruited to this study. Participants were excluded from the study if there was evidence knee pathology or there had been previous knee surgery. Written informed consent was provided and the procedure was approved by the University ethics committee $($ STEMH $=$ 637). 
Patella strap

167 A single patellar tendon strap was utilized in this investigation, (Bionix 1), which was worn on the dominant (right) limb in all participants. Participants performed their vertical jumps in the patellar tendon strap and no-patellar tendon strap conditions in a counterbalanced manner.

Procedure

Participants were required to complete five repetitions of a counter movement vertical jump in which they were required to use full arm swing and also to commence and land the jump on the force platform. The landing phase of the jump movement was quantified and was considered to have begun when $>20 \mathrm{~N}$ of vertical force was applied to the force platform and ended at point of maximum knee flexion (43).

178 Kinematics and ground reaction force (GRF) information were synchronously collected. Kinematic data were captured at $250 \mathrm{~Hz}$ via an eight camera motion analysis system (Qualisys Medical AB, Goteburg, Sweden) and kinetic data using a force platform (Kistler, Kistler Instruments Ltd., Alton, Hampshire) which operated at 1000 Hz. Dynamic calibration of the motion capture system was performed before each data collection session. To quantify lower extremity segments in six degrees of freedom, the calibrated anatomical systems technique was utilized (44). To define the anatomical frames of the pelvis, thigh, shank and foot retroreflective markers $(19 \mathrm{~mm})$ were positioned onto the, iliac crest, anterior superior iliac spine (ASIS), and posterior super iliac spine (PSIS). In addition, further markers were placed unilaterally onto the, medial and lateral malleoli, greater trochanter, medial and lateral 
femoral epicondyles calcaneus, first metatarsal and fifth metatarsal heads of the affected limb. Carbon-fiber tracking clusters comprising of four non-linear retroreflective markers were positioned onto the thigh and shank segments. In addition to these the foot segments were tracked via the calcaneus, first metatarsal and fifth metatarsal, and the pelvic segment was tracked using the PSIS and ASIS markers. The hip joint centre was determined using a regression equation, which uses the positions of the ASIS markers and the centres' of the ankle and knee joints were delineated as the mid-point between the malleoli and femoral epicondyle markers. The test-retest reliability of this marker set has been confirmed through previous analyses (45).

Static calibration trials were obtained with the participant in the anatomical position in order for the positions of the anatomical markers to be referenced in relation to the tracking clusters/markers. A static trial was conducted with the participant in the anatomical position in order for the anatomical positions to be referenced in relation to the tracking markers, following which those not required for dynamic data were removed. The $\mathrm{Z}$ (transverse) axis was oriented vertically from the distal segment end to the proximal segment end. The $\mathrm{Y}$ (coronal) axis was oriented in the segment from posterior to anterior. Finally, the $\mathrm{X}$ (sagittal) axis orientation was determined using the right hand rule and was oriented from medial to lateral.

In addition to the biomechanical information, the effects of the patella strap on knee joint proprioception were also examined using a weight bearing joint position sense test. This was conducted, in accordance with the procedure of Drouin et al., (46), whereby participants were assessed on their ability to reproduce a target knee flexion angle of $30^{\circ}$ whilst in single leg 
stance. To accomplish this, participants were asked to slowly squat to a knee flexion angle of $30^{\circ}$, which was verified using a handheld goniometer by the same researcher throughout data collection. Participants then held this position for 15 seconds during which time the knee criterion position was captured using the motion analysis system. Following this, participants were asked to return to a standing position and wait for 15 seconds, following which they reproduced the target angle as accurately as possible but without guidance via the goniometer. Again, this position was held for a period of 15 seconds and the replication trial was also collected using the motion analysis system. This above process conducted on three occasions in both the brace and no-brace conditions in a counterbalanced order and between each trial each participant walked for $20 \mathrm{ft}$ to eliminate any proprioceptive memory of the previous trial. The absolute difference in degrees calculated between the criterion and replication trials was averaged over the three trials to provide an angular error value in both brace and no-brace conditions, which was extracted for statistical analysis.

Following completion of the biomechanical data collection, in accordance with Sinclair et al., (47), participants were asked to subjectively rate the patella strap in relation to performing the movements without the device in terms of stability and comfort. This was accomplished using 3 point scales that ranged from $1=$ more comfortable, $2=$ no-change and $3=$ less comfortable and $1=$ more stable, $2=$ no-change and $3=$ less stable

\section{Processing}

Dynamic trials were processed using Qualisys Track Manager, and then exported as C3D files. Ground reaction force and marker data were filtered at $50 \mathrm{~Hz}$ and $15 \mathrm{~Hz}$ respectively using a low-pass Butterworth 4th order filter, and processed using Visual 3-D (C-Motion, 
236 Germantown, MD, USA). Internal moments were computed using Newton-Euler inverse237 dynamics, allowing net knee joint moments to be calculated. Angular kinematics of the knee joint were calculated using an XYZ (sagittal, coronal and transverse) sequence of rotations.

Patellofemoral loading was quantified using a model adapted from van Eijden et al., (48), in accordance with the protocol of Wilson et al., (49) in that co-contraction of the knee flexor musculature was accounted for. Hamstring and gastrocnemius forces were calculated in accordance with previously established procedures (50). Hamstring and gastrocnemius forces were multiplied by their moment arms relative to the knee flexion angle (51), and then summed to generate a knee flexor moment. The knee flexor moment was added to the net knee extensor moment quantified using inverse dynamics and divided by the quadriceps moment arm (4), to obtain quadriceps force adjusted for co-contraction of the knee flexors. Patellofemoral force was then quantified in accordance with the protocol of van Eijden et al., (48).

Patellofemoral joint stress was quantified by dividing the patellofemoral force by the patellofemoral contact area. Patellofemoral contact areas were obtained in accordance with the sex specific data of Besier et al., (52). Patellofemoral force (BW) and stress (KPa/BW) were normalized by dividing the net values by bodyweight.

In addition, Patellar tendon loading was quantified using a model similarly adapted from Janssen et al., (53). Again, the derived knee flexor moment was added to the net knee extensor moment quantified using inverse dynamics, and then divided by the moment arm of the patellar tendon, generating the patellar tendon force. The tendon moment arm was using 
the data of Herzog \& Read, (54). All patellar tendon forces were normalized by dividing the net values by bodyweight (BW). Patellar tendon forces (BW) were normalized by dividing the net values by bodyweight.

Following this, the three-dimensional knee joint kinematics, patellar tendon and patellofemoral kinetics were extracted during the entire landing phase and time normalized to 101 data points for each participant. In addition, because SPM utilizes time normalized data we also calculated the total patellofemoral/ patellar tendon force impulse (BW.s) and patellofemoral stress impulse $(\mathrm{KPa} / \mathrm{BW} \cdot \mathrm{s})$ using a trapezoidal function during the landing phase. Finally, the patellofemoral and patellar tendon force instantaneous loading rates $(\mathrm{BW} / \mathrm{s})$ were also quantified maximum increase in vertical force between adjacent data points.

\section{Statistical analyses}

Differences in lower extremity kinetics and kinematics during the landing phase were examined using 1-dimensional SPM approach using MATLAB 2017a (MATLAB, MathWorks, Natick, USA), in accordance with (40), via the source code available at http://www.spm1d.org/. In agreement with Pataky et al., (55), SPM was implemented in a hierarchical manner, analogous to a 2 (Patellar strap) x 2 (Gender) mixed ANOVA, with post-hoc analyses in the event of a significant interaction. The alpha $(\alpha)$ level for statistical significance for SPM was set at the 0.05 level. In addition to this, for patellofemoral/ patellar tendon impulse and instantaneous load rates descriptive statistics of means and standard deviations (SD) were calculated for each condition/ gender. Differences in patellofemoral/ 
patellar tendon impulse instantaneous loading rates (i.e. parameters that could not be contrasted using SPM) were examined using Bayesian factors (BF) to explore the extent to which the data supported the alternative $\left(\mathrm{H}_{1}\right)$ or null $\left(\mathrm{H}_{0}\right)$ hypotheses i.e. that there were or were no meaningful differences between patellar tendon strap and no-patellar tendon strap conditions for both males and females. Bayes factors were interpreted in accordance with the recommendations of Jeffreys, (56). Finally, participants' subjective ratings of stability and comfort were examined using Chi-squared $\left(X^{2}\right)$ tests. Discrete statistical tests were conducted using SPSS v25.0 (SPSS, USA).

\section{Results}

\section{Statistical parametric mapping}

No significant differences in knee joint kinematics were observed (Figure 1). However, for patellofemoral force there was a main effect of GENDER, which showed that females were associated with greater patellofemoral force during the early landing phase (Figure 2).

@@@FIGURE1 NEAR HERE@@@ @@@FIGURE 2 NEAR HERE@ @ @

\section{Discrete parameters}

For knee joint proprioception there was substantial evidence in support of $\mathrm{H}_{0}$ for both males $(\mathrm{BF}=0.25)$ and females $(\mathrm{BF}=0.32)$. For patellofemoral instantaneous load rate there was again substantial evidence in support of $\mathrm{H}_{0}$ for both males $(\mathrm{BF}=0.28)$ and females $(\mathrm{BF}=$ 
0.23). For the patellofemoral force integral there was substantial evidence for $\mathrm{H}_{0}$ in males $(\mathrm{BF}=0.20)$ and anecdotal evidence in females $(\mathrm{BF}=0.61)$. For the patellofemoral stress integral there was substantial evidence for $\mathrm{H}_{0}$ in males $(\mathrm{BF}=0.20)$ and anecdotal evidence in females $(\mathrm{BF}=0.78)$. For patellar tendon instantaneous load rate there was anecdotal evidence for $\mathrm{H}_{0}$ in males $(\mathrm{BF}=0.35)$ and substantial evidence in females $(\mathrm{BF}=0.24)$. Finally, for the patellar tendon integral there was substantial evidence for $\mathrm{H}_{0}$ in males $(\mathrm{BF}=0.21)$ and anecdotal evidence in females $(\mathrm{BF}=0.61)$.

Subjective ratings

In males, the subjective ratings of comfort indicated that, 3 participants rated that the tendon

In males, the subjective ratings of stability indicated that, 11 participants rated that the tendon strap improved perceived stability, 3 no-change and 0 reduced stability. The chi-squared test was significant $\left(X^{2}=13.86, \mathrm{P}<0.05\right)$ and significantly more participants found that the tendon strap enhanced knee stability. In females, the subjective ratings of stability indicated that, 9 participants rated that the tendon strap improved perceived stability, 3 no-change and 2 
reduced stability. The chi-squared test was significant $\left(X^{2}=6.14, \mathrm{P}<0.05\right)$ and significantly more participants found that the tendon strap enhanced knee stability.

\section{Discussion}

The aim of this investigation was to examine the influence of a patellar tendon strap on knee joint kinetics and kinematics during a vertical jump task, using SPM and Bayesian analyses. An investigation of this nature may provide important information regarding the effects of patellar tendon straps on the biomechanical parameters linked to the aetiology of chronic knee pathologies.

Importantly, the current investigation showed using both SPM and Bayesian analyses that neither patellofemoral of patellar tendon loading parameters were meaningfully influenced as a function of the patellar tendon strap. This finding opposes those of Lavagnino et al., (14), examined the effects of a patellar tendon strap on localized strain at the proximal aspect of the patellar tendon typically affected by tendinopathy. They measured participants in a static position at $60^{\circ}$ of knee flexion rather than during a dynamic situation, which may explain the lack of agreement between the two investigations. This observation may be clinically meaningful as both chronic patellar tendinopathy and patellofemoral pain syndrome are mediated through excessive and frequent loading $(15,28)$. Therefore, the findings from the current investigation indicate that patellar tendon straps may not be effective in attenuating the biomechanical parameters linked to chronic knee injuries. 
However, the examination using SPM did show that during the early landing phase, females where associated with statistically larger patellofemoral joint forces than males. This observation concurs with those observed previously in different movements (57), in that females were associated with enhanced patellofemoral joint loading compared to age matched males. Importantly epidemiological analyses have shown that females are at increased risk from patellofemoral pain in relation to age-matched males (58). Given the proposed association between knee joint loading and patellofemoral joint pathology (28), the current investigation appears to insight into the high incidence of patellofemoral pain in female athletes.

In addition, similar to the kinetic analyses, the current investigation showed that threedimensional knee joint kinematics were not meaningfully influenced as a function of the patellar tendon strap. This observation, does not agree with those of Rosen et al., (34) who found a patellar tendon strap produced less hip rotation, knee adduction and ankle inversion in those with and without patellar tendinopathy. Athletes with patellar tendinopathy have been shown to exhibit decreased knee flexion angles during jumping activities (62). Similarly, those with patellofemoral pain have been shown to exhibit increased knee flexion, knee adduction and hip internal rotation in relation to non-pathological controls (29). As such, the findings from the current investigation indicate that patellar tendon straps may not unequivocally reduce the three-dimensional kinematic parameters linked to the aetiology of chronic knee pathologies.

372 The current investigation also showed that knee joint proprioception was similarly not 373 meaningfully affected by the patellar tendon strap. This observation opposes those of 
previous analyses indicating that patellar tendon straps improve knee proprioception. It is possible that the differences observed between analyses is due to the different approaches used to measure knee proprioception, as although de Vries et al., (36) and de Vries et al., (37) also utilized knee joint position sense analyses, this was not assessed during weight bearing. However, despite this the current study did reveal that perceived knee joint stability was significantly improved when using the tendon strap. This is an interesting observation taking into account the absence of meaningful alterations in knee joint kinetics, kinematics and proprioception and thus it is not possible in the context of the current investigation to determine the clinical importance of improved perceived stability. Nonetheless, in future longitudinal analyses is it recommended that the clinical implications of perceived changes be examined further using patellar tendon straps.

A potential limitation to the current investigation is that patellofemoral and patellar tendon loading indices were obtained using a musculoskeletal modelling based approach. This was a necessary procedure due to the invasive nature of obtaining in vivo musculoskeletal kinetic measurements. Although this approach accounts for co-contraction of the knee flexor musculature, further work is still required to improve the efficacy of subject specific musculoskeletal models of the knee joint, making possible further developments in clinical biomechanical analyses. In addition, a further drawback to the current study is that it noninjured participants were examined, meaning that the findings are not generalizable to athletes with existing knee joint pathologies. Future, analyses should therefore seek to determine the clinical efficacy of patellar tendon straps as treatment modalities for athletes with existing knee injuries. 


\section{Conclusion}

399 This study showed using SPM and Bayesian analyses that patellofemoral and patellar tendon 400 kinetic parameters were not affected as a function of the patellar tendon strap. Similarly, 401 three-dimensional knee joint kinematics were not meaningfully influenced as a function of 402 the patellar strap. The findings did show however that the patellar strap helped to increase 403 perceived knee stability. The current investigation therefore indicates that the utilization of a 404 patellar tendon strap akin to the device used in the current study does not appear to reduce the 405 biomechanical parameters linked to the aetiology of chronic knee pathologies, during vertical 406 jump landing movements.

\section{Acknowledgements}

409 We acknowledge the assistance of Gareth Shadwell and Philip Stainton.

\section{Conflict statement}

412 The author(s) declare no potential conflicts of interest with respect to the research, 413 authorship, and/or publication of this article.

\section{$415 \quad$ Funding}

416 The author(s) received no financial support for the research, authorship, and/or publication of

417 this article. We would however like to acknowledge our institutions undergraduate research intern program (https://www.uclan.ac.uk/students/support/research/urip.php). 


\section{References}

421

1. Warburton DE, Nicol CW, Bredin SS. Health benefits of physical activity: the evidence. CMAJ. 2006; 174: 801-809.

2. Lachman S, Boekholdt SM, Luben RN, Sharp SJ, Brage S, Khaw KT, Wareham, N. J. Impact of physical activity on the risk of cardiovascular disease in middle-aged and older adults: EPIC Norfolk prospective population study. Eur J Prev Cardiol. 2018; 25: 200-208.

3. Sparling PB, Owen N, Lambert EV, Haskell WL (2000). Promoting physical activity: the new imperative for public health. Health Educ Res. 2000; 15: 367-376.

4. Haljaste K, Unt E. Relationships between physical activity and musculoskeletal disorders in former athletes. Coll Antropol. 2010; 34: 1335-1340.

5. Lee C, Porter KM. Prehospital management of lower limb fractures. Emerg Med J. 2005; $22: 660-663$.

6. Agel J, Akesson K, Amadio PC, Anderson M, Badley E, Balint G, Bjorke PA. The burden of musculoskeletal conditions at the start of the new millennium. World Health Organ Tech Rep Ser. 2003; 919: 219-225.

7. Hootman JM, Dick R, Agel J. Epidemiology of collegiate injuries for 15 sports: summary and recommendations for injury prevention initiatives. J Athl Train. 2007; 42: 311-319.

8. Kujala UM, Kvist M, Österman K. (1986). Knee injuries in athletes. Sports Med. 1986; 3: 447-460.

9. Ingram JG, Fields SK, Yard EE, Comstock RD. Epidemiology of knee injuries among boys and girls in US high school athletics. Am J Sports Med. 2008; 36: 1116-1122. 

profile of sports-related knee injuries in northern India: An observational study at a tertiary care centre. J Clin Orthop Trauma. 2016; 7: 207-211.

11. Thomas MJ, Wood L, Selfe J, Peat G. Anterior knee pain in younger adults as a precursor to subsequent patellofemoral osteoarthritis: a systematic review. BMC Musc Disord. 2010; 11: 201-205.

12. Cook JL, Khan KM, Purdam CR. Conservative treatment of patellar tendinopathy. Phys Ther Sport. 2001; 35: 291-294.

13. Lian ØB, Engebretsen L, Bahr R. Prevalence of jumper's knee among elite athletes from different sports: a cross-sectional study. Am J Sports Med. 2005; 33: 561-567.

14. Lavagnino M, Arnoczky SP, Dodds J, Elvin N. Infrapatellar straps decrease patellar tendon strain at the site of the jumper's knee lesion: a computational analysis based on radiographic measurements. Sports Health. 2011; 3: 296-302.

15. Rudavsky A, Cook J. Physiotherapy management of patellar tendinopathy. J Physiother. 2014; 60: 122-129.

16. Reinking MF. Current concepts in the treatment of patellar tendinopathy. Int J Sports Phys Ther. 2016; 11: 854-866.

17. Maffulli N, Wong J, Almekinders LC. Types and epidemiology of tendinopathy. Clin J Sport Med. 2003; 22: 675-692.

18. Pascual-Garrido C, Rolón A, Makino A. Treatment of chronic patellar tendinopathy with autologous bone marrow stem cells: a 5-year-followup. Stem Cells Int. 2012; doi: 10.1155/2012/953510.

19. Cook JL, Khan KM, Harcourt PR, Grant M, Young DA, Bonar SF. A cross sectional study of 100 athletes with jumper's knee managed conservatively and surgically. The 
Victorian Institute of Sport Tendon Study Group. Br J Sports Med. 1997; 31: 332336.

20. Kettunen JA, Kvist M, Alanen E, Kujala UM. Long-term prognosis for jumper's knee in male athletes. A prospective follow-up study. Am J Sports Med. 2002; 30: 689692.

21. Crossley KM, Stefanik JJ, Selfe J, Collins NJ, Davis IS, Powers CM, McConnell J, Vicenzino B, Bazett-Jones BM, Esculier J-F, Morrissey D, Callaghan MJ. Patellofemoral pain consensus statement from the 4th International Patellofemoral Pain Research Retreat, Manchester. Part 1: Terminology, definitions, clinical examination, natural history, patellofemoral osteoarthritis and patient-reported outcome measures. Br J Sports Med. 2016; 50: 839-843.

22. Halabchi F, Abolhasani M, Mirshahi M, Alizadeh Z. Patellofemoral pain in athletes: clinical perspectives. Open Access J Sports Med. 2017; 8: 189-203.

23. Oakes JL, McCandless P, Selfe J. Exploration of the current evidence base for the incidence and prevalence of patellofemoral pain syndrome. Physical Therapy Reviews. 2009; 14: 382-387.

24. Foss KD, Myer GD, Magnussen RA, Hewett TE. Diagnostic differences for anterior knee pain between sexes in adolescent basketball players. J Athl Enhanc. 2014; 3: $1814-1820$.

25. Blond L, Hansen L. Patellofemoral pain syndrome in athletes: a 5.7-year retrospective follow-up study of 250 athletes. Acta Orthopædica Belgica. 1998; 64: 393-400.

26. Smith BE, Selfe J, Thacker D, Hendrick P, Bateman M, Moffatt F, Logan P. Incidence and prevalence of patellofemoral pain: A systematic review and metaanalysis. PloS one. 2018; 13: e0190892. 
27. Maclachlan LR, Matthews M, Hodges PW, Collins NJ, Vicenzino B. The psychological features of patellofemoral pain: a cross-sectional study. Scand J Pain. 2018; 18: 261-271.

28. Farrokhi S, Keyak JH, Powers CM. Individuals with patellofemoral pain exhibit greater patellofemoral joint stress: a finite element analysis study. Osteoarthritis Cartilage. 2011; 19: 287-294.

29. McKenzie K, Galea V, Wessel J, Pierrynowski M. Lower extremity kinematics of females with patellofemoral pain syndrome while stair stepping. J Orthop Sports Phys Ther. 2010; 40: 625-632.

30. Nimon G, Murray D, Sandow M, Goodfellow J. Natural history of anterior knee pain: a 14-to 20-year follow-up of nonoperative management. J Pediatr Orthop. 1998; 18: $118-122$.

31. Eijkenboom JFA, Waarsing JH, Oei EH, Bierma-Zeinstra SM, van Middelkoop M. Is patellofemoral pain a precursor to osteoarthritis? Patellofemoral osteoarthritis and patellofemoral pain patients share aberrant patellar shape compared with healthy controls. Bone Joint Res. 2018; 7: 541-547.

32. Capin JJ, Snyder-Mackler L. The current management of patients with patellofemoral pain from the physical therapist's perspective. Ann Joint. 2018; 3: 40-43.

33. Demirbüken İ, Özyürek S, Angın S. The immediate effect of patellar tendon strap on weight-bearing asymmetry during squatting in patients with unilateral knee osteoarthritis: A pilot study. Prosthetics and orthotics international. 2016; 40: 682688.

34. Rosen AB, Ko J, Simpson KJ, Brown CN. Patellar tendon straps decrease pain and may alter lower extremity kinetics in those with patellar tendinopathy during jump landing. Int J Athl Ther Train. 2017; 22: 51-57. 
35. Rosen AB, Ko J, Simpson KJ, Brown CN. Patellar tendon straps decrease pre-landing quadriceps activation in males with patellar tendinopathy. Phys Ther Sport. 2017; 24: 13-19.

36. de Vries AJ, van den Akker-Scheek I, Haak SL, Diercks RL, van der Worp H, Zwerver J. Effect of a patellar strap on the joint position sense of the symptomatic knee in athletes with patellar tendinopathy. J Sci Med Sport. 2017; 20: 986-991.

37. de Vries AJ, van den Akker-Scheek I, Diercks R., Zwerver J, van der Worp H. The effect of a patellar strap on knee joint proprioception in healthy participants and athletes with patellar tendinopathy. J Sci Med Sport. 2016; 19: 278-282.

38. Whyte EF, Kennelly P, Milton O, Richter C, O’Connor S, Moran KA. The effects of limb dominance and a short term, high intensity exercise protocol on both landings of the vertical drop jump: implications for the vertical drop jump as a screening tool. Sports Biomech. 2018; 17: 541-553.

39. Pataky TC. Generalized n-dimensional biomechanical field analysis using statistical parametric mapping. J Biomech. 2010; 43: 1976-1982.

40. Pataky TC, Robinson MA, Vanrenterghem J. Vector field statistical analysis of kinematic and force trajectories. J Biomech. 2013; 46: 2394-2401.

41. Pullenayegum EM, Thabane L. Teaching Bayesian statistics in a health research methodology program. J Stat Educ. 2009; 17: 21-23.

42. Ashby D. Bayesian statistics in medicine: a 25 year review. Stat Med. 2006; 25: 35893631.

43. Sinclair J, Hobbs SJ, Selfe J. (2015). The influence of minimalist footwear on knee and ankle load during depth jumping. Res Sports Med. 2015; 23: 289-301. 
44. Cappozzo A, Catani F, Leardini A, Benedeti MG, Della CU. Position and orientation in space of bones during movement: Anatomical frame definition and determination. Clin Biomech. 1995; 10: 171-178.

45. Sinclair J, Taylor PJ, Greenhalgh A, Edmundson CJ, Brooks D, Hobbs SJ. The testretest reliability of anatomical co-ordinate axes definition for the quantification of lower extremity kinematics during running. J Hum Kinet. 2012; 35: 15-25.

46. Drouin JM, Houglum PA, Perrin DH, Gansneder BM. Weight bearing and nonweight-bearing knee joint reposition sense are not related to functional performance. J Sport Rehab. 2003; 12: 54-66.

47. Sinclair JK, Vincent H, Richards JD. Effects of prophylactic knee bracing on knee joint kinetics and kinematics during netball specific movements. Phys Ther Sport. 2017; 23: 93-98.

48. van Eijden TM, Kouwenhoven E, Verburg J, Weijs WA. A mathematical model of the patellofemoral joint. J Biomech. 1986; 19: 219-229.

49. Willson JD, Ratcliff OM, Meardon SA, Willy RW. Influence of step length and landing pattern on patellofemoral joint kinetics during running. Scandinavian Journal of Medicine \& Sci Sports. 2015; 25: 736-743.

50. DeVita P, Hortobagyi T. Functional knee brace alters predicted knee muscle and joint forces in people with ACL reconstruction during walking. J Applied Biomech. 2001; 17: $297-311$.

51. Spoor CW, van Leeuwen JL. Knee muscle moment arms from MRI and from tendon travel. J Biomech. 1992; 25: 201-206.

52. Besier TF, Draper CE, Gold GE, Beaupre GS, Delp SL. Patellofemoral joint contact area increases with knee flexion and weight-bearing. J Orthop Res. 2005; 23: 345350. 
53. Janssen I, Steele JR, Munro BJ, Brown NA. Predicting the patellar tendon force generated when landing from a jump. Med Sci Sports Exerc. 2013; 45: 927-934.

54. Herzog W, Read LJ. Lines of action and moment arms of the major force-carrying structures crossing the human knee joint. J Anat. 1993; 182: 213-230.

55. Pataky TC, Robinson MA, Vanrenterghem J. Region-of-interest analyses of onedimensional biomechanical trajectories: bridging OD and 1D theory, augmenting statistical power. Peer J. 2016; 4: 2652-2664

56. Jeffreys H. Theory of probability (3rd Ed.). 1961. Oxford, UK: Oxford University Press.

57. Sinclair J, Selfe J. Sex differences in knee loading in recreational runners. J Biomech. 2015; 48: 2171-2175.

58. Robinson RL, Nee RJ. Analysis of hip strength in females seeking physical therapy treatment for unilateral patellofemoral pain syndrome. J Orthop Sports Phys Ther. 2007; 37: 232-238.

59. Rosen AB, Ko J, Simpson KJ, Kim SH, Brown CN. Lower extremity kinematics during a drop jump in individuals with patellar tendinopathy. Orthop J Sports Med. 2015; 3: doi: 10.1177/2325967115576100.

\section{$\underline{\text { Figure labels }}$}




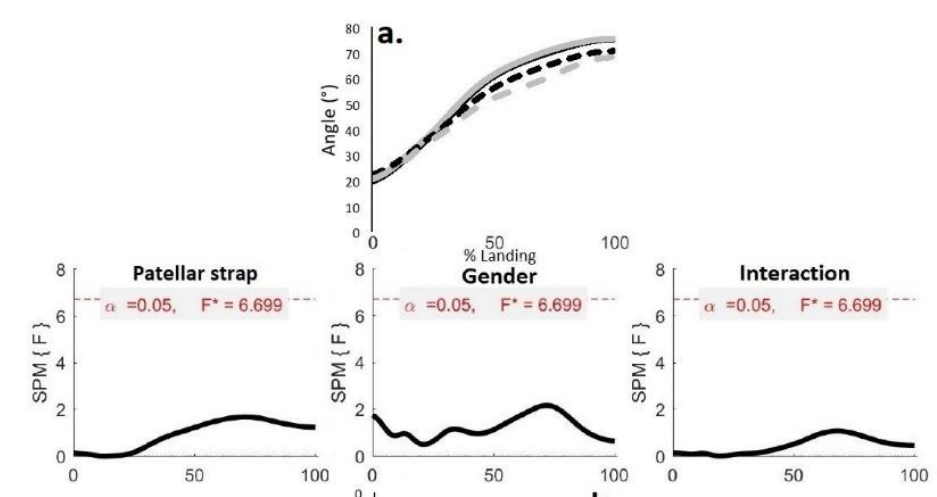

b.
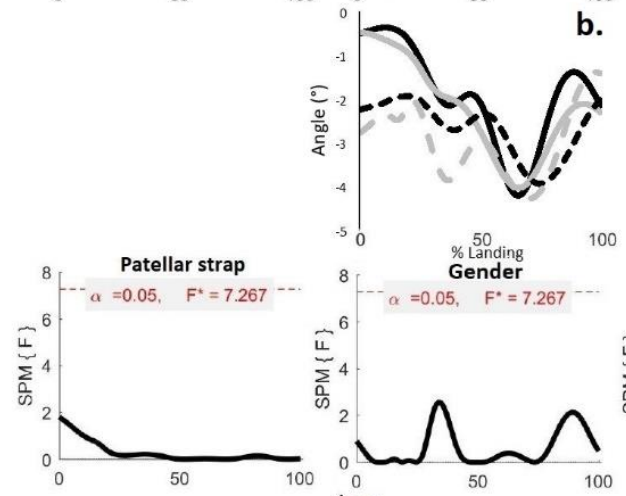

8. Interaction
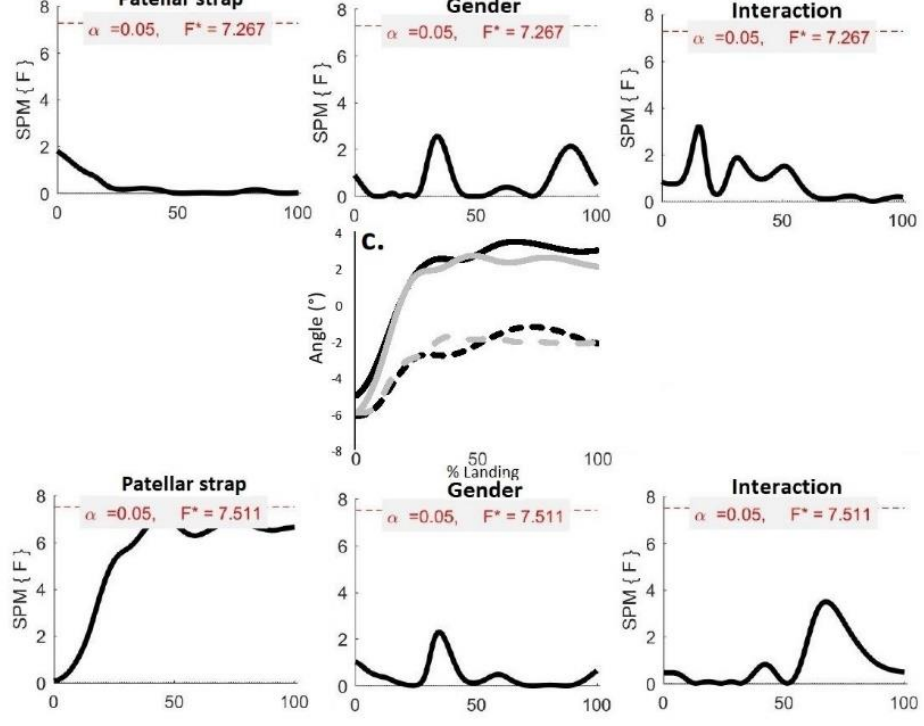

584 Figure 1: Three-dimensional knee kinematics $(\mathrm{a} .=$ sagittal plane, $\mathrm{b} .=$ coronal plane $\& \mathrm{c} .=$

585 transverse plane) and associated SPM comparisons (black = male no patellar tendon strap,

586 grey $=$ male patellar tendon strap, black dash $=$ female no patellar tendon strap, grey dash $=$

587 female patellar tendon strap). 

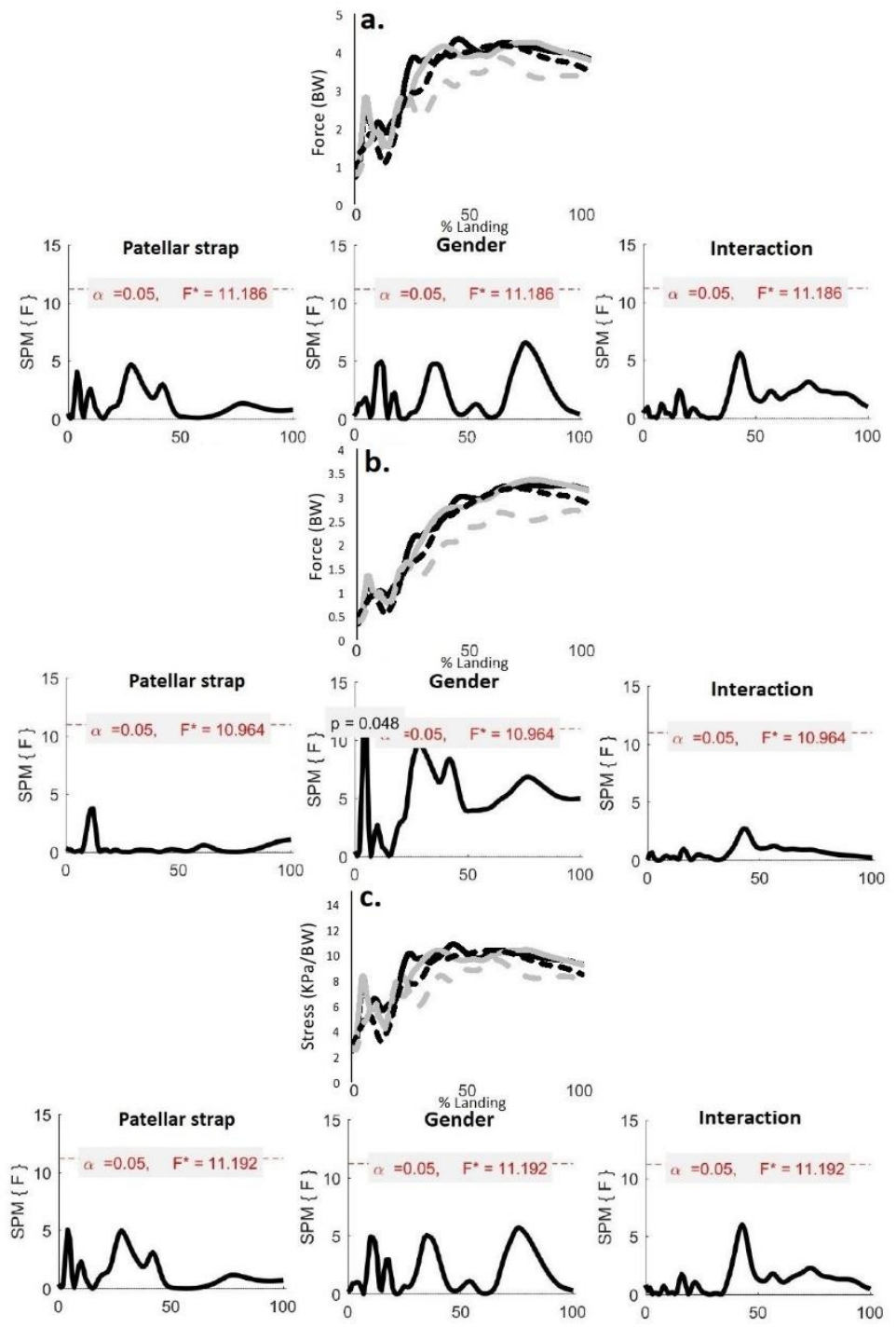

589

590 Figure 2: Knee kinetics $(\mathrm{a} .=$ patellar tendon force, $\mathrm{b} .=$ patellofemoral force $\&$ c. $=$

591 patellofemoral stress) and associated SPM comparisons (black = male no patellar tendon

592 strap, grey $=$ male patellar tendon strap, black dash $=$ female no patellar tendon strap, grey

593 dash

$=\quad$ female

patellar

tendon

strap). 
Table 1: Discrete (Mean \& SD) kinetic and proprioception parameters.

\begin{tabular}{|c|c|c|c|c|c|c|c|c|}
\hline & \multicolumn{4}{|c|}{ Male } & \multicolumn{4}{|c|}{ Female } \\
\hline & \multicolumn{2}{|c|}{ Patellar strap } & \multicolumn{2}{|c|}{ No-patellar strap } & \multicolumn{2}{|c|}{ Patellar strap } & \multicolumn{2}{|c|}{ No-patellar strap } \\
\hline & Mean & SD & Mean & SD & Mean & SD & Mean & SD \\
\hline Proprioception error $\left({ }^{\circ}\right)$ & 5.51 & 4.40 & 4.69 & 4.50 & 5.61 & 3.68 & 4.52 & 2.85 \\
\hline Patellofemoral instantaneous load rate (BW/s) & 293.18 & 85.07 & 308.98 & 122.14 & 253.82 & 123.74 & 244.73 & 95.39 \\
\hline Patellofemoral force integral (BW·s) & 0.49 & 0.17 & 0.50 & 0.21 & 0.45 & 0.30 & 0.38 & 0.23 \\
\hline Patellofemoral stress integral (KPa/BW) & 1.64 & 0.55 & 1.66 & 0.63 & 1.63 & 0.84 & 1.38 & 0.59 \\
\hline Patellar tendon instantaneous load rate (BW/s) & 572.03 & 163.09 & 606.97 & 244.24 & 487.69 & 230.48 & 473.49 & 192.41 \\
\hline Patellar tendon integral (BW·s) & 0.66 & 0.19 & 0.68 & 0.27 & 0.60 & 0.35 & 0.52 & 0.26 \\
\hline
\end{tabular}

